\title{
Predictors of family communication of one's organ donation intention in Switzerland
}

\author{
Alexandra Volz Wenger · Thomas D. Szucs
}

Received: 29 May 2009/Revised: 5 March 2010/Accepted: 24 March 2010/Published online: 22 April 2010

(C) The Author(s) 2010. This article is published with open access at Springerlink.com

\begin{abstract}
Objectives Family members continue to play a prominent role in decisions to donate organs at the time of death. Prior knowledge of the deceased's intention to donate was identified as an important influential factor in the donation decision-making process. This study examined what factors lead to family communication of a person's wish regarding organ donation.

Methods A population-based survey was used to identify the prevalence of people who had informed family members of their intention to donate. Associated factors were evaluated using bivariate and multivariate analyses.

Results Multivariate analysis revealed that communication to a family member of the intention to donate organs was more likely if the respondent had a signed donor card $(\mathrm{OR}=10.23, \mathrm{CI}=5.25-19.93)$, had a family discussion on organ donation or transplantation $(\mathrm{OR}=7.12, \mathrm{CI}=$ 4.91-10.34), had a partner and knew his or her attitude to organ donation $(\mathrm{OR}=5.76, \mathrm{CI}=4.20-7.90)$, had previously personally had a good look at the issue of organ donation $\quad(\mathrm{OR}=2.59, \quad \mathrm{CI}=1.79-3.75)$, was rather younger $(\mathrm{OR}=0.98, \mathrm{CI}=0.97-0.99)$, was of Swiss nationality $(\mathrm{OR}=2.21, \mathrm{CI}=1.25-3.91)$, felt that he or she was sufficiently informed $(\mathrm{OR}=2.10, \mathrm{CI}=1.50$ 2.94 ), had the information necessary to come to an appropriate decision on organ donation and-although this
\end{abstract}

\footnotetext{
A. Volz Wenger ( $₫)$

Division of Biomedicine, Federal Office of Public Health,

Bern, Switzerland

e-mail: alexandra.volz@bag.admin.ch

T. D. Szucs

Institute for Social and Preventive Medicine,

University of Zurich, Zurich, Switzerland
}

relation may be weaker-were (rather) willing to become an organ donor after death $(\mathrm{OR}=1.41, \mathrm{CI}=1.01-1.97)$. Conclusions Our findings highlight the need for public education and community campaigns to promote the need to share with others, the intention to donate and to increase people's knowledge on this issue.

Keywords Organ donation - Family communication · Knowledge $\cdot$ Attitudes

\section{Introduction}

In recent decades, organ transplants have developed throughout the world into a successful therapy to treat organ failure. In the final stage of renal failure, a kidney transplant is a cost-effective treatment, which permanently improves quality of life. In cases of the failure of liver, lungs or heart a transplant is the only possible treatment for most patients. As a result of the imbalance between the steadily growing demand for organs and the stagnant supply, more and more organs of marginal quality have to be transplanted, and the prognosis is less good. Longer waiting periods also have a negative effect on the prognosis.

Information given to families, and having a donor card that has been filled in make it easier for the hospital staff to determine whether patients are prepared to donate their organs after their death. As organ donation rarely, if ever, takes place without the consent of the next of kin, it is a key issue whether the relatives are aware of the wishes of the deceased. When the next of kin are made aware of the intentions of the deceased, the family usually respects those wishes (Radecki and Jaccard 1997; Siminoff and Lawrence 2002). An investigation carried out by a Swiss transplant 
centre has shown that family refusal was the main reason for the exclusion of registered potential organ donors and it seems that there is a trend towards an increase in family members declining organ donation (Seiler et al. 2006). We need to see the decision to donate organs as a family persuasive process rather than a solely personal, individual choice (Afifi et al. 2006).

Several studies suggest that next-of-kin donation decisions are multi-determined, with various patient and family characteristics, prior knowledge of the deceased's intention to donate, request patterns, understanding of brain death, the number of other family members present at the time the request is made and the degree of satisfaction with the medical care received all identified as influential factors in the decision to donate (Siminoff et al. 2001; Burroughs et al. 1998; DeJong et al. 1998; Martinez et al. 2001; Boulware et al. 2002a; Rodrigue et al. 2006). The importance of communicating to family members the intention to be a donor, especially to those who are likely to be approached about organ donation in the event of death is also underscored by the findings of Rodrigue et al. 2006: knowing the deceased's donation intentions and organ donation beliefs at the time of the donation approach are the most important decision-making factors for the next of kin. The wishes expressed by the deceased are usually carried out if family members are aware of the intention to donate and if donation intentions are not known, consent will not be obtained in the vast majority of such instances. Knowledge of the deceased's intentions helps to reduce ambiguity and conflict among family members. Consent is less likely when there is more family conflict and family members are not in agreement about donation (Martinez et al. 2001; Rodrigue et al. 2006). Therefore, this is an important communication process to study. In this context, assessing the level and sources of related information is essential for defining educational strategies. Most of the literature about decision-making and indicating one's decision about organ donation has focused on improving consent for organ donation and on those who are willing to donate. Little research has been done on people indicating the decision about organ donation regardless of the direction of the donation intention. Indicating the decision about organ donation by people willing and unwilling to donate organs facilitates the donation request process for the health care team in charge and for families who are being approached. When uncertain, the fear of proceeding against the wishes of the deceased is an obstacle to organ donation and a source of regret on the decision taken on behalf of the next of kin. The objectives of this analysis were to examine which factors led to family notification of a person's wishes regarding organ donation, differences in the level of information that people say they have about organ donation and which sources of related information were used.

\section{Methods}

The work is based on data obtained in the 2005 survey of the population carried out by the Federal Office of Public Health on the transplantation of organs, tissues and cells (Monitoring of the Transplant Act 2004). In this written questionnaire, 5,500 randomly selected households were approached, and received the questionnaire in the language of their linguistic area. The random sample with disproportionate stratification by language group included 2,500 addresses in the German-speaking area, 1,500 in the French-speaking area and 1,500 in the Italian-speaking part of Switzerland. For each household selected, the person chosen to fill in the questionnaire was the person, aged over 18 , who would be the next to have his or her birthday. There were no replacements for non-respondents. 2,062 households $(40 \%)$ returned the completed questionnaire. It was possible to include a total of 1,721 questionnaires in this analysis. The data were weighted by linguistic area due to the oversampling of the French-speaking and Italianspeaking areas to be representative of the Swiss population. Participants were representative regarding gender and age. The initial postal questionnaire asked participants about predictors of interest such as socio-demographic characteristics, willingness to donate and attitudes related to organ donation, important behaviour such as having a signed donor card or where they searched for information and whether they felt sufficiently informed about organ donation and transplantation.

The bivariate relationships between the predictors of interest and family communication were compared. Participants who mentioned having informed family members of their intention to donate were compared with those who did not inform the family. Measures of association for categorical data were assessed using the Chi-square statistic, while $t$ tests assessed interval variables. Independent variables measured on a six-point Likert Scale (ranging from strongly disagree to strongly agree) were collapsed into two categories (agree vs. disagree). There was no neutral point in the scale.

Multivariate logistic regressions were performed using sociodemographics, attitudes related to organ donation and transplantation medicine and the self-reported level of information about organ donation and transplantation. All predictors in the logistic regression were entered simultaneously. Education, willingness to become an organ donor after death and all predictor variables that were statistically significant $(P<0.05)$ for the outcome were included and were entered simultaneously in the final model.

This analysis investigates the pattern of utilization of sources of information by status of family notification and then describes the proportion of participants reporting sufficient knowledge about transplantation, again with a 
group comparison. Knowledge about organ donation and tissue donation has been measured in past research in different ways (Feeley 2007): General information refers to the person's perception of how informed he or she is on the topic and typically is a single item. Multiple-item knowledge indexes in true/false format were used; answering a certain percentage of knowledge item questions correctly may not be particularly meaningful (Feeley 2007). In this study, knowledge data are based on self-reporting, indicating whether respondents feel sufficiently informed about organ donation and whether they reach the critical level of information necessary to come to an appropriate decision on organ donation. So our definition of knowledge refers to the term "general information" and reflects whether people feel comfortable with their individual knowledge, rather than evaluating differences in general and medical knowledge about organ donation. Data were analysed using SPSS version 13. All data were tested for multicollinearity. The primary aim of this study was to further examine factors that may be relevant for the communication of donation intentions to family members.

\section{Results}

1721 respondents were included in this analysis: female $915(53 \%)$, male 807 (47\%). 66.5\% of them stated that they were (rather) likely to donate their organs after death. $16.3 \%$ had a signed donor card. $45 \%$ believed they had communicated their donation intention to family members and $48 \%$ indicated that they had a partner, whose attitude to organ donation is known. Table 1 summarizes the sociodemographic characteristics of each group. Respondents who had informed family members of their desire to donate were younger (mean age 46.7 vs. 50.1, $P<0.001$ ), were more likely to be women (59.4 vs. $48.0 \%$, $P<0.001)$, were more likely to have received further education (38.1 vs. $31.1 \%, P<0.01)$ and were more likely to have a good current state of health (93.9 vs. $89.6 \%$, $P<0.01)$.

Table 2 summarizes comparisons between respondents who had or had not informed family members of their intention to donate. Compared with respondents who had not informed family members, respondents who had informed the family were more likely to be willing to donate their organs after their death (79.1 vs. $56.0 \%$, $P<0.001)$, more likely to have signed a donor card (33.9 vs. $1.7 \%, P<0.001$ ), more likely to have personally gone into the issue of organ donation ( 88.4 vs. $47.4 \%$, $P<0.001)$, more likely to have gathered media information on the topic in recent months (44.1 vs. $27.7 \%$, $P<0.001)$, more likely to know anyone who has been affected by transplantation ( 30.8 vs. $21.6 \%, P<0.001)$, more likely to have had a family discussion on organ donation or transplantation (92.1 vs. $39.2 \%, P<0.001)$, more likely to know the attitude of their partner to organ donation ( 73.4 vs. $27.6 \%, P<0.001)$, more likely to trust transplantation medicine (74.6 vs. $62.1 \%, P<0.001)$ and the process of organ allocation (80.2 vs. $68.3 \%$, $P<0.001$ ), more likely to perceive the benefits of donation, more likely to feel sufficiently informed about organ donation (54.1 vs. $19.3 \%, P<0.001)$ and less likely to have negative feelings and concerns about organ donation and bodily mutilation after death. Responses indicated that concerns were shared across groups but were significantly more prevalent among members of the group without family communication. In particular, relatively high proportions stated that they perceived it as unnatural to

Table 1 Sociodemographic characteristics of the sample according to family communication status of a person's intention to donate organs

\begin{tabular}{|c|c|c|c|}
\hline & $\begin{array}{l}\text { Family communication: } \\
\text { yes } \\
(n=777) \\
\%\end{array}$ & $\begin{array}{l}\text { Family communication: } \\
\text { no } \\
(n=944) \\
\%\end{array}$ & $P$ value \\
\hline \multicolumn{4}{|l|}{ Gender $(n=1,721)$} \\
\hline Female & 59.4 & 48.0 & \multirow[t]{2}{*}{$<0.001$} \\
\hline Male & 40.6 & 52.0 & \\
\hline Age $(n=1721)^{\mathrm{a}}$ & $46.7(15.5)$ & $50.1(15.6)$ & $<0.001$ \\
\hline Further education $(n=1,715)$ & 38.1 & 31.1 & 0.003 \\
\hline Swiss Germans $(n=1,721)$ & 69.7 & 73.1 & 0.130 \\
\hline Swiss nationality $(n=1,721)$ & 93.4 & 90.5 & 0.031 \\
\hline Lives in the country $(n=1,718)$ & 39.0 & 39.1 & 1.000 \\
\hline Has children $(n=1,684)$ & 66.6 & 64.9 & 0.496 \\
\hline Belongs to a church or religious community $(n=1,717)$ & 19.4 & 15.7 & 0.055 \\
\hline Current state of health (rather) good $(n=1,711)$ & 93.9 & 89.6 & 0.002 \\
\hline
\end{tabular}

${ }^{a}$ Mean (SD) for the factor measured on the interval scale 
Table 2 Bivariate associations between family communication status of a person's intention to donate organs and their attitudes related to organ donation and transplantation

\begin{tabular}{|c|c|c|c|}
\hline & $\begin{array}{l}\text { Family } \\
\text { communication: } \\
\text { yes }(n=777) \\
\text { Agreeing }^{\mathrm{a}}(\%)\end{array}$ & $\begin{array}{l}\text { Family } \\
\text { communication: } \\
\text { no }(n=944) \\
\text { Agreeing }^{\mathrm{a}}(\%)\end{array}$ & $P$ value \\
\hline I am prepared to provide one of my organs immediately after my death & 79.1 & 56.1 & $<0.001$ \\
\hline I have a donor card & 33.9 & 1.7 & $<0.001$ \\
\hline I have personally gone into the issue of organ donation & 88.4 & 47.4 & $<0.001$ \\
\hline $\begin{array}{l}\text { I have already discussed the issue of organ donation or transplantation with my } \\
\text { family (with friends) }\end{array}$ & 92.1 & 39.2 & $<0.001$ \\
\hline I know the attitude of my partner to organ donation & 73.4 & 27.6 & $<0.001$ \\
\hline I feel that I am sufficiently informed about organ donation/transplantation & 54.1 & 19.3 & $<0.001$ \\
\hline I feel that I am not sufficiently informed to decide for or against organ donation & 13.7 & 46.3 & $<0.001$ \\
\hline If I donate my organs after death, that gives added meaning to my life & 40.0 & 31.1 & $<0.001$ \\
\hline By donating organs I can help people who are suffering & 85.0 & 80.8 & 0.025 \\
\hline It is important to donate organs so that lives can be saved & 86.0 & 80.7 & 0.005 \\
\hline $\begin{array}{l}\text { Most people who are important to me are in favour of me donating my organs } \\
\text { after my death }\end{array}$ & 74.7 & 54.4 & $<0.001$ \\
\hline I have great confidence in transplant medicine & 74.6 & 62.1 & $<0.001$ \\
\hline I believe that in Switzerland allocation of organs is done fairly & 80.2 & 68.3 & $<0.001$ \\
\hline $\begin{array}{l}\text { It is unnatural to prolong the life of people who are terminally ill by organ } \\
\text { transplantation }\end{array}$ & 26.7 & 31.9 & 0.023 \\
\hline I feel uncomfortable with the thought of my organs being removed & 21.3 & 41.1 & $<0.001$ \\
\hline Organ removal is a violation of dead people and should not happen & 11.4 & 18.2 & $<0.001$ \\
\hline For religious reasons one should not donate organs & 6.1 & 11.8 & $<0.001$ \\
\hline I reject the removal of organs from a cadaver for fear of disfiguring the body & 6.5 & 17.5 & $<0.001$ \\
\hline I find the topic unpleasant, as it reminds me of my death & 14.9 & 35.5 & $<0.001$ \\
\hline $\begin{array}{l}\text { Do you know anyone among your family or friends who has been affected by } \\
\text { transplantation (as a donor or recipient)? }\end{array}$ & 30.8 & 21.6 & $<0.001$ \\
\hline $\begin{array}{l}\text { In recent months I have gathered media information on the topic of organ } \\
\text { donation or transplants }\end{array}$ & 44.1 & 27.7 & $<0.001$ \\
\hline
\end{tabular}

a $\%$ agreeing reflects individuals who responded either strongly agree, agree or rather agree

prolong the life of terminally ill people by organ transplants and felt uncomfortable to think of their organs being removed or they found the topic unpleasant as it reminded them of their own death. The groups differed in the proportions who felt that they were not sufficiently informed to be able to make a decision about donating (13.7 vs. 46.3\%, $P<0.001)$.

Table 3 shows self-reported sources of information in respondents who had and had not informed family members of their desire to donate. Respondents who had informed family members used each possible source of information more frequently except for television and radio. Using sources of information other than television, radio and health insurance seem to be associated with family communication, making people feel sufficiently informed. Respondents who had informed family members more frequently reported a sufficient level of information about organ donation (Table 2). Multivariate analysis (Table 4) revealed that communication of organ donation intention to a family member was more likely if the respondent had a signed donor card, had had a family discussion on organ donation or transplantation, had a partner and knew his or her attitude to organ donation, had previously personally had a good look at the issue of organ donation, was of Swiss nationality, felt sufficiently informed, had the information necessary to come to an appropriate decision on organ donation, were rather younger and were (rather) willing to become an organ donor after death. The overall model is statistically significant and predicted family communication in $83.3 \%$ of the cases.

\section{Discussion}

The primary purposes of this investigation were to better understand the factors that predicted an individual's family notification of their decision to donate organs and to 
Table 3 Source of information, by status of family communication

\begin{tabular}{lcrr}
\hline & $\begin{array}{l}\text { Family communication: } \\
\text { yes }(n=777) \\
\text { Citing }(\%)\end{array}$ & $\begin{array}{l}\text { Family communication: } \\
\text { no }(n=944) \\
\text { Citing }(\%)\end{array}$ & $P$ value \\
\hline Print media & 63.1 & 57.2 & 0.016 \\
Television & 58.7 & 61.3 & 0.286 \\
Radio & 27.0 & 24.3 & 0.220 \\
Internet & 7.7 & 3.9 & 0.001 \\
Brochures & 28.1 & 15.1 & $<0.001$ \\
Events & 6.0 & 2.2 & $<0.001$ \\
Family & 47.9 & 16.7 & $<0.001$ \\
Friends & 39.9 & 23.8 & $<0.001$ \\
Family doctor & 10.3 & 5.5 & $<0.001$ \\
Pharmacy/drugstore & 11.7 & 5.2 & $<0.001$ \\
Hospital/medical facilities & 18.0 & 11.0 & $<0.001$ \\
Health insurance & 3.3 & 3.4 & 1.000 \\
School & 12.9 & 6.6 & $<0.001$ \\
\hline
\end{tabular}

Table 4 Factors associated with family communication of a person's wishes regarding organ donation from logistic regression model (odds ratios, $95 \%$ confidence interval, $P$ value)

\begin{tabular}{|c|c|c|c|}
\hline Variable & OR & $95 \% \mathrm{CI}$ & $P$ value \\
\hline Sex & 1.35 & $0.97-1.86$ & 0.073 \\
\hline Age & 0.98 & $0.97-0.99$ & 0.001 \\
\hline Further education & 0.96 & $0.70-1.32$ & 0.801 \\
\hline Swiss nationality & 2.21 & $1.25-3.91$ & 0.007 \\
\hline Willingness to become an organ donor after death & 1.41 & $1.01-1.97$ & 0.047 \\
\hline Signed donor card & 10.23 & $5.25-19.93$ & $<0.001$ \\
\hline I have already personally gone into the issue of organ donation & 2.59 & $1.8-3.75$ & $<0.001$ \\
\hline Had a family discussion & 7.12 & $4.91-10.34$ & $<0.001$ \\
\hline I have a partner and know his or her attitude to organ donation & 5.76 & $4.20-7.90$ & $<0.001$ \\
\hline Feel sufficiently informed about organ donation and transplantation & 2.10 & $1.50-2.94$ & $<0.001$ \\
\hline Feel insufficiently informed to decide for or against organ donation & 0.45 & $0.32-0.64$ & $<0.001$ \\
\hline Trust in the fair allocation of organs & 1.38 & $0.97-1.94$ & 0.071 \\
\hline
\end{tabular}

examine the role of behaviour (signed organ donor card), attitudes to and knowledge about organ donation. Several studies have been carried out on organ donation and family communication. Even in studies where family communication was examined, the topic was usually peripheral to the goal of predicting willingness to donate. The results of this study show that respondents' family communication of their wishes regarding organ donation is linked to having a signed donor card, having had a family discussion on organ donation or transplantation, knowing the donation intentions of the partner, having already gone into the issue of organ donation, being of Swiss nationality, feeling sufficiently informed, being rather younger and to the willingness to become an organ donor after death. The strongest predictor is having a signed donor card. The expressed intention regarding organ donation in the form of a signed donor card increases the probability that the wish to donate is also documented orally, especially if the issue of organ donation has already been discussed within the family and there is a partner whose attitude to the issue is known. Studies by Guadagnoli et al. 1999 and Morgan and Miller 2002 showed that signing an organ donor card stimulates family discussions about organ donation. It also appears from our results that when people feel knowledgeable about organ donation and feel rather positive about it, they may be more confident in approaching family members about their wishes. Knowing the facts and being comfortable with the information may facilitate keeping the discussion focused and explaining to the family member what the decision to be an organ donor entails. There is consensus between existing studies that knowledge is an important predictor of willingness to talk to family 
members about organ donation (Guadagnoli et al. 1999; Morgan and Miller 2001, 2002; Morgan et al. 2003; Radecki and Jaccard 1999).

The two study groups differ with respect to self reported knowledge. There is a real lack of information among people who have not informed family members of their desire to donate, as about half of them do not reach the relevant level of knowledge compared with $14 \%$ of those who have communicated with their family. We defined the relevant level of knowledge as that such as to have sufficient information to decide for or against organ donation. To come to an appropriate decision, a critical amount of information is necessary.

In both groups a high proportion of people were supportive of the humanitarian act involved in organ donation, while it seems that in the group without family communication people felt less certain and more uncomfortable about the topic and there was a very low proportion of signed donor cards. However, it has to be considered that statements such as feeling uncomfortable with the idea of having an organ removed and finding it unnatural to extend life by organ transplant appear to represent beliefs that are widespread within the population and are shared by a proportion of both groups. Many key barriers to the adoption of health behaviour may be non-cognitive; this does not necessarily mean that they cannot be addressed effectively (Sanner 1994; Morgan et al. 2008). The greater concerns of those who have not informed family members of their intention to donate may be reflected partly by their lower level of information and preparedness to donate organs. Non-cognitive concerns are a strong negative predictor of attitudes towards donation, while talking to family members about the intention to donate organs is driven by knowledge (Morgan et al. 2008). Our results confirm these findings as attitudes related to organ donation and transplantation including non-cognitive concerns had no effect on the multivariate analysis.

There was a significant, negative predictive relationship between increasing age and family communication. Although the number of donors over the age of 50 has increased significantly in the last decade, older adults are generally less willing to be organ donors (Boulware et al. 2002b). Family members of older adults are less likely to consent when asked (Siminoff et al. 2001; Rodrigue et al. 2006; Sheehy et al. 2003). It is possible that older adults and those making decisions on their behalf believe that advanced age precludes donating organs or that it renders organs less desirable for transplantation (Rodrigue et al. 2006; Siminoff et al. 2007). Education initiatives should inform middle-aged and older adults about the increased use of ageing donors with an ageing waiting-list population and should motivate them to make their end of life wishes known. Interestingly, this is quite consistent with a recent survey of the public carried out in Switzerland (Schulz et al. 2006), which showed that increasing age has a negative impact on engaging in organ donation behaviours in all three language groups. Similar to our study, the 2006 survey found that demographics including gender had no significant effect on the multivariate analysis. In our evaluation, the influence of gender was only shown at the bivariate level. Although the influence of the variable Swiss nationality was rather weak at the bivariate level, at the multivariate level it was a significant predictor and should be taken into consideration as the effect is possibly underestimated because of the language barrier.

Respondents who had talked to family members about their intention to donate used all the possible sources of information more frequently, except for television and radio. There is still little use of the Internet but this will probably increase regularly in the coming decades. It seems to be strongly related to having a professional occupation (Seematter-Bagnoud and Santos-Eggimann 2007). It is probable that showing more interest on the subject leads to people using sources of information other than television or radio, which seems to help people to be sufficiently informed to reach an appropriate decision and to talk to family members about it. Retrieving information in print media such as newspapers or brochures and through personal contacts such as family, friends and health professionals might improve communication on this complex topic. The electronic media are perhaps less appropriate for this. A factor analysis, analysing the influence of different sources of information on people's attitude to organ donation concluded that media such as information provided by health professionals, attending talks and discussions about organ donation with family and friends had the most impact on attitudes towards organ donation (Conesa et al. 2004). The media are the only sources of information about organ donation that the public is exposed to on a regular basis. Information from the media forms the basis of what is discussed in interpersonal contexts, but it did not have a significant impact on knowledge and attitude by itself (Morgan et al. 2008). These discussions with friends and family members appear to be supplementary to gather information about the issue and to make people adopt a less fearful stance towards donation. There is also a concern that entertainment may miseducate people, supplying inaccurate information through medical dramas and daytime serials (Morgan et al. 2008).

This analysis has several limitations. The data in the study are not longitudinal and the design is not experimental. As such it is impossible to establish temporal order. Reliance on self-reporting of organ donation conversations can be considered a limitation of the study as it relies on people's recollection of a conversation that may have taken 
place some time ago and it is not confirmed by a family member. A certain amount of social desirability may have affected people's responses and the absence of a measure of moral norms must be noted.

In conclusion, the results of this investigation offer insight in predictors of communicating organ donation intentions to family members and highlight the need for public education and community campaigns to promote the necessity of sharing intentions to donate organs with others and to seek to increase people's knowledge on the issue. The needs of older people and the migrant population to have information must be considered specifically in order to offer specific, easy accessible sources of information tailored to their needs. Public education aimed at encouraging individuals to make a decision on organ donation, and to communicate that decision to their family, while also providing information may be the best way to go.

Acknowledgments The authors would like to thank the Sozialforschungsstelle of Zurich University for their efforts in data collection.

Open Access This article is distributed under the terms of the Creative Commons Attribution Noncommercial License which permits any noncommercial use, distribution, and reproduction in any medium, provided the original author(s) and source are credited.

\section{References}

Afifi W, Morgan S, Stephenson M, Morse C, Harrison T, Reichert T, Long S (2006) Examining the decision to talk with family about organ donation: applying the theory of motivated information management. Commun Monogr 73(2):188-215

Boulware LE, Ratner LE, Cooper LA, Sosa JA, LaVeist TA, Powe NB (2002a) Understanding disparities in donor behavior: race and gender differences in willingness to donate blood and cadaveric organs. Med Care 40(2):85-95

Boulware LE, Ratner LE, Sosa JA, Cooper LA, LaVeist TA, Powe NR (2002b) Determinants of willingness to donate living related and cadaveric organs: identifying opportunities for intervention. Transplantation 73:1683-1691

Burroughs TE, Hong BA, Kappel DF, Freedman BK (1998) The stability of family decisions to consent or refuse organ donation: would you do it again? Psychosom Med 60:156-162

Conesa C, Ríos Zambudio A, Ramírez P, Canteras M, Rodríguez M, Parrilla P (2004) Influence of different sources of information on attitude toward organ donation: a factor analysis. Transpl Proc 36:1245-1248

DeJong W, Franz H, Wolfe S, Nathan H, Payne D, Reitsma W, Beasley C (1998) Requesting organ donation: an interview study of donor and nondonor families. Am J Crit Care 7:13-23

Feeley T (2007) College students' knowledge, attitudes, and behaviors regarding organ donation: an integrated review of the literature. J Appl Soc Psychol 37(2):243-271
Guadagnoli E, Christiansen CI, DeJong W, McNamara P, Beasley C, Christiansen E, Evanisko M (1999) The public's willingness to discuss their preference for organ donation with family members. Clin Transpl 13:342-348

Martinez JM, Lopez JS, Martin A, Martin MJ, Scandroglio B, Martin JM (2001) Organ donation and family decision-making within the Spanish donation system. Soc Sci Med 53:405-421

Monitoring of the Transplant Act, Synthesebericht der Nullmessung 2004/2005. http://www.transplantinfo.ch

Morgan SE, Miller JK (2001) Communicating about gifts of life: the effect of knowledge, attitudes, and altruism on behavior and behavioral intentions regarding organ donation. J Appl Commun Res 30:163-178

Morgan SE, Miller JK (2002) Beyond the organ donor card: the effect of knowledge, attitudes, and values on willingness to communicate about organ donation to family members. Health Commun 14:121-134

Morgan SE, Miller JK, Arasaratnam LA (2003) Similarities and differences between African-Americans and European-Americans attitudes, knowledge and willingness to communicate about organ donation. J Appl Soc Psychol 33(4):693-715

Morgan S, Stephenson M, Harrison T, Afifi W, Long S (2008) Facts versus feelings. J Health Psychol 13:644-658

Radecki CM, Jaccard J (1997) Psychological aspects of organ donation: a critical review and synthesis of individual and nextof-kin donation decisions. Health Psychol 16(2):183-195

Radecki CM, Jaccard J (1999) Signing an organ donation letter: the prediction of behavior from behavioral intentions. J Appl Soc Psychol 29:1833-1853

Rodrigue JR, Cornell DL, Howard RJ (2006) Organ donation decision: comparison of donor and nondonor families. Am J Transpl 6:190-198

Sanner M (1994) Attitudes toward organ donation and transplantation. A model for understanding reactions to medical procedures after death. Soc Sci Med 38:1141-1152

Schulz P, Nakamoto K, Brinberg D, Haes J (2006) More than nation and knowledge: cultural micro-diversity and organ donation in Switzerland. Patient Educ Couns 64:294-302

Seematter-Bagnoud L, Santos-Eggimann B (2007) Sources and level of information about health issues and preventive services among young-old persons in Switzerland. Int J Public Health 52:313-316

Seiler CA, Bischoff P, Nett PC, Candinas D (2006) Abnehmende Organspendebereitschaft als nationales Problem: Im Engagement liegt der Lösungsansatz. Schweizerische Ärztezeitung 87(4):143-150

Sheehy E, Conrad SL, Brigham LE (2003) Estimating the number of potential organ donors in the United States. N Engl J Med 349:667-674

Siminoff LA, Lawrence RH (2002) Preferences about organ donation: does it make a difference? J Trauma 53:754-760

Siminoff LA, Gordon N, Hewlett J, Arnold RM (2001) Factors influencing families' consent for donation of solid organs for transplantation. JAMA 286:71-77

Siminoff LA, Mercer MB, Graham G, Burant C (2007) The reasons families donate organs for transplantation: implications for policy and practice. J Trauma 62(4):969-978 